\title{
Evaluating retrospective experiential learning as process in scholarship on a work based professional doctorate
}

\section{John Fulton}

University of Sunderland, UK

\section{Catherine Hayes}

University of Sunderland, UK

\begin{abstract}
Acknowledging retrospective experiential learning as a unique contribution to knowledge in the context of the workplace is the fundamental focus of the work-based professional doctorate. This report details an evaluation of a 'Second Generation' professional doctorate programme. The programme provides a mechanism for both learning development and the acknowledgement and development of pre-existing, disciplinespecific, professional practice. Evaluation was used as a means of highlighting how the theory-praxis gap might be bridged via translational knowledge construction. Semistructured interviews were undertaken with eleven doctoral candidates to explore their experiences and perceptions of the programme. The interviews were then transcribed and thematically analysed during which a "base superstructure model" was identified. This model identified the underpinning skills of critical reflection, investigation and adaptive capacity necessary to inform and facilitate the research phase of the professional doctorate programme. The facilitation and upskilling of doctoral candidates in the use of emergent technology was identified as the basis for the development of professional and academic practice. The role of the doctoral supervisor, as a facilitator of the development of these skills, was also established as pivotal to learning development for doctoral candidates; in terms of developing their 'base super-structure' to become independent, reflective and adaptive learners.
\end{abstract}

Keywords: work-based learning; learning development; practice-based research; professional doctorate. 


\section{Introduction}

The work-based professional doctorate is a mechanism of acknowledging the proactive, and often longstanding, contribution to professional practice that mature doctoral candidates have made. The professional doctorate has an equivalency with the traditional Doctor of Philosophy (PhD), which is more appropriately equipped to meet the requirements of everyday professional practice (Lester, 2004). Higher Education Institutions (HEls) across the United Kingdom (UK) have experienced a significant rise in demand for practice-based or professional doctorate programmes, with a particular and emphatic focus on work-based professional practice (Costley and Stephenson, 2007). This study represents the evaluation of initial student experience across a professional doctorate pathway. It was undertaken with the aim of identifying the key challenges candidates perceived in their learning journeys.

\section{Background}

Recognition that diverse arrays of doctoral programmes are available, both nationally and internationally, is well established (Fulton et al., 2012; Gill and Hoppe, 2009). In the UK, the professional doctorate has gained increasing popularity since the mid-1990s. The title of professional doctorate encompasses a range of programmes, many of which are discipline or subject specific. These titles acknowledge professional identity in their title, for example: ‘Doctor of Engineering', 'Doctor of Education' or 'Doctor of Nursing'. A further classification of professional doctorate, which Maxwell (2003) seminally termed 'the second generation' professional doctorate, integrates the acknowledgement of pre-existing experiential learning with the concept of professional practice (this now will be referred to as the 'work-based professional doctorate'). The work-based professional doctorate essentially transcends professional boundaries by focusing on the context of professional practice; since, in the world of work, professional boundaries are often intangibly blurred. 


\section{Sustainable working relationships between Higher Education Institutions (HEls) and industry}

Since the latter part of the $20^{\text {th }}$ century there has been an increasing focus on the need for more definitive and sustainable links between the workplace and academic institutions. Historically, this emanated from 'The Roberts Report' (Roberts, 2002), which emphasised the need for the development of transferable skills in doctoral pathways. The most recent, 'The Dowling Report' (Dowling, 2015), continued to emphasise the importance of embedded links between HEls and industry. Drucker (1999) had initially popularised this idea and proposed the concept of the 'knowledge worker'; this could be operationally defined as those employees who were involved in the active creation, adaptation and application of knowledge to practice.

\section{Knowledge as a commodity}

In the context of universities and also in terms of consumerism, knowledge is being increasingly regarded as a commodity, which can be packaged, marketed and sold (Benlow, 2015). Institutional strategies necessitate resilient collaborative links to be made with industry and key stakeholders and a willingness to translate theoretical knowledge into practice (Hakkarainen et al., 2014). All of which adds complexity to the provision of taught doctoral learning pathways; to drive this agenda necessitates a needs-led approach to educational provision. Associated with this is the requirement for knowledge generated from research to be strategically and directly related to employment and academic provision (Fink, 2006). This necessitates a dialogic loop between HEls and industry, most specifically in relation to knowledge transfer partnership working and the development of academic curricula that fully meet the workforce development needs of organisations.

\section{The challenges of using retrospective experiential learning in doctoral pathways}

Gibbons et al. (1994) seminally proposed that there were typologies of knowledge, referred to as 'Mode 1' knowledge and 'Mode 2' knowledge: 'Mode 1' was identified as being the uni-disciplinary or "purist" type and 'Mode 2', as the knowledge underpinning and generated from applied practice. 'Mode 1' knowledge is primarily generated in the context 
of formal academic institutions and is characterised by homogeneity and autonomy, alongside being subject to traditional forms of quality assurance that characterise the peerreview process. 'Mode 2' knowledge is, by its very nature, focused on real world issues and problems and, as such, takes a multi-disciplinary approach, which emphasises the applied nature of knowledge production; it is heterogeneous and quality assurance stems from social accountability and processes of critical reflexivity. Estimating the contextual significance of experiential learning in the integration and acknowledgement of prior learning has been defined as a pivotal consideration in both learning development and the academic credibility of doctoral pathways (Herrington, Reeves and Oliver, 2014).

\section{Academic requirements}

As part of academic requirements, work-based professional doctoral candidates must demonstrate innovation and original development in the context of their professional practice which has wider impact upon their professional discipline. As Costley and Lester (2012) clearly identify, the work based professional doctorate is aimed at mid-career professionals who usually have the positional authority to tangibly impact on practice. This capacity was originally outlined by Doncaster and Lester (2002) as:

Implying a capacity to move beyond competence to being able to work effectively in unpredictable and changing contents. (Doncaster and Lester, 2002, p.91)

The capacity to articulate this competence is also presented as pivotal to evidencing impact in professional practice (Kamler and Thomson, 2014).

\section{The challenge of developing practice and professional activity}

The work-based professional doctorate is a relatively recent innovation and is traditionally designed to focus on the development of practice and professional activity. Most programmes offer a taught component and candidates spend some time working up their proposal. However, as candidates are often experienced practitioners working at a senior level in their respective disciplines, this requirement can present challenges in terms of 
academic writing; information retrieval skills; and selecting an appropriate methodology by which to establish the focus of their work.

\section{Learning development and the research process of the work-based professional doctorate}

Stubb, Pyhältö and Lonka (2014) have extensively analysed core concepts of the research process in relation to learning development. Their analysis can be directly aligned with the capacity of doctoral candidates to frame and contextualise their individual contribution to professional practice. How this learning development can be facilitated for established practitioners was an issue most recently engaged with by Bimrose et al. (2014) who concluded that this level of innovation could not be sustained without the proven capacity for authentic and credible facilitation of doctoral level learning. It is here that discipline specificity is significant and differentiation between the 'researching professional' and the 'professional researcher' emerges as a means of definitively distinguishing between the $\mathrm{PhD}$, as a traditional learning pathway, and the equal, but parallel, pathway offered by the professional doctorate (Schildkraut and Stafford, 2015).

\section{Structure and uptake of the professional doctorate pathway}

This evaluation makes specific reference to an established and successful professional doctorate programme, which has been validated and operational for six years. To date, over 25 candidates have completed the programme and a further 80 candidates are at various stages of progression through the programme. A range of professional backgrounds are represented through the annual cohorts - core discipline representations being: allied healthcare professionals and managers; senior bankers; educationalists (from primary, secondary and tertiary educational sectors); and police and military services. Despite the differences in professional background, there is a commonality amongst candidates which cannot necessarily be ascertained from their collective professional groupings. In practice, individuals' collective understanding and experience often transcends professional boundaries, contributing significantly to the development of fundamentally new communities of practice within each specific cohort. 
The programme is iteratively evaluated, both formally and informally, as part of routine quality assurance processes. Evaluations have been overwhelmingly positive with doctoral candidates emphasising that there is much appreciation for programmes with a high degree of relevance to practice.

Unlike candidates from other programmes, including many PhD candidates, those doing professional doctorates have considerable experience, evidenced usually by them being acknowledged as being at the forefront of their professional disciplines or having already made a significant contribution to professional practice. Particular challenges lie in articulating the inherent issues surrounding learning development and exploring how approaches can be individually tailored to meet the needs of established professionals.

\section{Assumptions and pre-suppositions}

In terms of academic provision, academics have also to challenge assumption and presupposition about the capacity of doctoral candidates to engage with academic writing, information retrieval and the articulation of higher order thinking skills, particularly for those candidates from backgrounds dissociated from academia and immersed in pragmatism. Professional doctoral candidates usually occupy positional authority at the fore of their professional discipline however this does not always necessitate specific skill sets such as those characterised by academic coursework submissions. For this reason it is imperative that the development and progression of these skills are embedded early into the doctoral learning journey.

\section{Programme structure and design}

The current doctoral schema is structured into taught and work-based and/or research components. The taught component consists of three compulsory modules: 'critical reflective practice'; 'research methods' and 'planning and contextualisation'. 'Critical reflective practice' requires the candidates to complete two reflective accounts using a recognised and theoretically integrated process of reflective practice, whereas 'research methods' requires them to identify fundamental methods of enquiry dominant in their recognised community of practice. As part of the process they identify the inherent 
methodological implications of the chosen methods of enquiry. In the 'contextualisation and planning' module, doctoral candidates develop a detailed research proposal which serves as the basis for developmental progression of their initial work. A professional masters option is available to candidates who may wish to leave the programme at an early threshold level of achievement, or in instances where their proposal is judged as being unlikely to fulfil doctoral threshold level requirements; although to date this option has never been utilised by any of the doctoral candidates. The taught component is delivered via designated study days, where deliberate emphasis is placed not on the acquisition of heavily theoretical knowledge but on the facilitation of those higher order thinking skills necessary to provide a positive and tangible trajectory for the development of their work.

Upon completion of the taught element of the doctoral programme (the first academic year), doctoral candidates then work in an interactive dialogue with their supervisor to shape and implement their research proposal in practice. The outcome of this is a report of 20,000 to 30,000 words, which contextualises and frames their (usually pragmatic and work-based) research idea in the extant published literature. This is then aligned with a question-led methodological approach. Upon completion of these two stages, it is possible for candidates to demonstrate the tangible impact of their proposed research to their individual area of professional practice. The report is accompanied by the submission of a portfolio of evidence which demonstrates achievement in terms of the tangible impact of their project on professional practice in the workplace. The report, whilst shorter, bears similarity to a traditional $\mathrm{PhD}$ thesis in terms of its anatomical structure. It encompasses a theoretically integrated literature review illustrating the contemporaneous aspects of practice that frame the study and an underpinning methodology which illustrates the particular theoretical framework of the research question or statement, results section and subsequent discussion of findings.

It is important to mention here that both the portfolio and report are individually negotiated elements of assessment and, as such, there is no one prescribed formula for construction in order to encourage creative and innovative approaches to portfolio building. However the portfolio provides the findings of the study which are ultimately cross-referenced to the report. As such the portfolio demonstrates how each professional doctoral candidate contributes to practice in a fundamentally unique manner. 


\section{Methodology}

This study aimed to explore the specific learning needs of candidates on a work-based professional doctorate programme. A cross section of doctoral candidates, in representative numbers, were selected from the initial, middle and final stages of the professional doctorate programme. This study reflects the views of candidates in the middle category (i.e. 2-3 years into the programme), all of whom had completed the compulsory taught component and were at a substantially developed stage of their doctoral studies. Semi-structured interviews were executed with the 11 candidates who were initially selected on a purposive basis so that, as the interviews progressed, the principles of theoretical sampling could be followed. In this context, theoretical sampling was defined as being the selection of the sample which would best facilitate the researcher's emergent understanding of the phenomena (Glaser and Strauss, 1967). This necessitated a constant comparative process of data collection and thematic data analysis. Subsequent respondents beyond the initial interviews were chosen as to how they could develop and inform the emergent categories. For example, several interviewees (particularly those working in the public sector) experienced changes in their professional role and functioning, which could mean a significant adaptation to their doctoral learning journey and were subsequently deliberately chosen. Correspondents were interviewed on the basis of a predetermined schedule which served as a basic guide to give focus and structure to the conversation; unexpected issues and themes were also explored. Interviews were taped and transcribed verbatim and subsequently thematically analysed via open coding (Strauss and Corbin, 1998). Upon completion of open coding, narrative analysis was used to capture the evaluative aspects of the dialogue (Labov and Waletzky, 1967). Matheson (2005) outlines a method based on Lobov's work: the basic premise is that in any account (or story) there are distinct components, and in telling a story, the individual phrases can be classified into scene setting (in which the scene is identified and outlined), details of action and evaluative aspects. Researchers such as Van Dijk (2008) have used the same principle to identify the evaluative aspects and argue that this represents the "true" views of the participants.

Each category identified was then purposefully divided into "stories" or distinct narratives and the scene setting, details of action and evaluative comments were identified (of which there were relatively few). The evaluative comments were grouped into sub-categories, which informed the development trajectory of the research. 


\section{Results}

All candidates reported positive experiences of the professional doctorate programme, and perceived it as an excellent vehicle for the development of professional practice. They identified significant challenges in entering the programme both in terms of their particular learning needs and in selecting an appropriate methodological approach from which they could develop their work. In particular they determined they needed an underpinning structure or, as one respondent put it, 'scaffolding'. This foundational underpinning framework was strategically aligned with the need for the development of transferable skills of information retrieval, a critical academic writing style and skills of critical reflective practice and reflexivity. Having achieved these basic skills candidates could then go on and develop their work in credible manner. This can be represented (by borrowing a metaphor from Marxist theory) as a 'base superstructure' model, the base being the underpinning which then facilities the development of practice, which then allows the candidate to develop their work to the doctoral level (Figure 1).

\section{Figure 1. Base-superstructure model}

Superstructure

Base

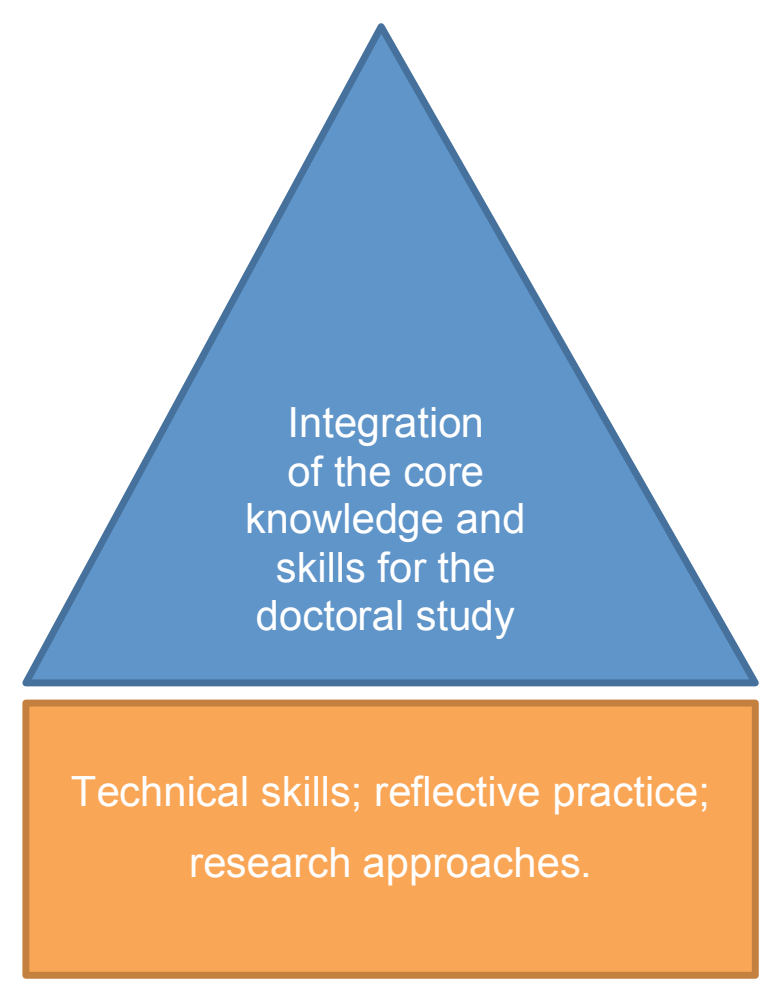


Initial ideas could tangibly be mapped onto the doctoral programme structure; doctoral candidates needed to build a skills-base both in terms of advanced technical proficiency and their ability to critically reflect on practice. The support from supervisors was an integral part of this foundational base. This facilitated the doctoral candidate in combining the constituent elements in a fundamentally unique and creative manner. This provided a foundation for the creative element of practice, which allowed for the further development and integration of work-based practice.

\section{Underpinning skills}

All candidates indicated they often came unprepared for sessions and found accessing and management of information challenging (both in terms of selectivity and retrieval skills). The amount of information available was perceived as 'overwhelming'; the management of information also presented particular challenges, in terms of discerning quality and the subsequent management of reference registries.

The initial stages of the programme consisted of the doctoral candidates liaising with academic librarians to gain necessary skills of information retrieval. Whilst this may have appeared to academics to be a very basic intervention it was a clear area for concern to doctoral candidates and, via this structured induction, they perceived a distinct benefit from the time invested. A key example of this was when one doctoral candidate reported:

I am self-taught and I wish more of the practical side was given at the beginning.

In the initial stage of the programme, candidates undertook a series of taught modules, and the doctoral candidates all valued input from the teaching team, one saying:

...they gave me a discipline... when you are putting stuff together you can lose your way a little.

When they commenced their actual study the supervisory team were deemed to be very important and were an essential element perceived to underpin the programme, one candidate said: 
The supervisor is without a doubt the key player.

Candidates also valued peer support and the contribution to their learning development from their doctoral cohort peers, stating:

We found it was quite supportive in that we would motivate each other. We have a good synergy in the classroom...a range of backgrounds.

Senior students could support novices in practice and use their own placement learning experiences as a guide to the process. As one student noted:

The year three students have helped me a lot in practice. I have learnt from them how they went about things themselves to get to where they are now. Through their advice, I take some of the plain paperwork home, to familiarise myself with it. This has really helped my confidence.

\section{Reflective practice}

The reflective element was illuminating from a holistic perspective; it gave the doctoral candidates an opportunity to examine their individual practices and to provide justification for why they were involved in their particular signature disciplines, which shaped their professional identities. The candidates were required to undertake a critical reflective practice module and, while the thrust of the module was founded on professional practice and professional identity, many candidates stated that the process of the module delivery had facilitated them in critical introspection and processes of critical reflexivity. This integrated their perceptions and experiential learning from practice into the process of critical reflection:

I found this very therapeutic...new community...the professional doctorate actually got you to stand outside of yourself and look at yourself from a distance.

Many found the process akin to therapy: 
...stand back and look at your career; what went well and what didn't go so well and how you have evolved over the years you have spent in professional practice.

...it was almost like having your own counsellor.

\section{Strategies for development of work}

Undertaking a professional doctorate necessitates approaching the academic workload in a logical and systematic manner, which emanates from structuring and theoretically integrating work and aligning it with identifiable methodological approaches. It is here that precision in relation to terminology and the need to differentiate between methodology and method is imperative to distinguish 'doctoralness'. As a general finding, doctoral candidates were concerned with the methodological framework which could potentially underpin their work. Methodologies are the framework in which the research study is framed and structured, deriving from an ontological and epistemological stance which is in turn linked specifically to theory or theoretical perspectives. For example, the grounded theory is methodologically linked to symbolic interactionism. Here, research methods are the pragmatic processes undertaken to perform data collection and ought to be congruent with methodological origin.

Many candidates present initially with a retrospective body of work, which they wish to develop further and incorporate into their final doctoral submission. It is here that establishing an overarching framework can present the need to challenge traditional assumptions about professional practice, if methods-led rather than question-driven approaches to systematic inquiry are to be adopted. Doctoral candidates found it challenging to establish an area of enquiry and to also develop the skills to drive this forward. In real terms this could mean time wasted, at least in the initial phases of the work:

Perhaps for others who hadn't gone through that, a bit more scaffolding was required.

For those doctoral candidates who came from a "scientific background", the affective domain skills presented particular challenges, and an assumption could be made that 
qualitative approaches were an easy option, which, with exposure, was quickly contradicted:

Qualitative research is a completely different ball game ...I made some big mistakes and wasted my time.

The implementation of a methodological framework provided a degree of structure which harnessed and facilitated creativity:

...I thought now there's potential here. I tried ethnographic techniques on myself and found it so powerful it really, really challenged my patterned thinking.

...auto-ethnography - finding out about it was a pivotal moment.

\section{Super-structure}

Having established this skill base the candidates could develop their practice in a unique and creative manner, as described by one candidate who stated:

Creatively that time to think in a different way, just giving that different perspective. Even getting them to challenge how they think is relatively easy, you know... but if the root cause of the thing that's gone wrong is based on a wrong assumption they have held with them all of their lives (something that happened when they were a child perhaps) it's really challenging for them to triple loop and challenge those assumptions in the first place. By engaging the creative mind a little bit more, it just breaks that pattern, even if it's just for a moment, to give you that alternative perspective, in going through that challenge and thinking about that, that enables a different mind-set completely.

Interestingly, it was the integration of methodological frameworks and processes of critical introspection which facilitated this creativity:

...seemed to bring us back to a time when we were all playful and creative in our approach...it seemed to engage that part of the mind. 
Integral to the process, there was an evident structural support underpinning the creative process attributable to the chosen research methodology:

...I think they need some structure: it's like if you're learning music, I think you do need to know the chord. I play guitar, I mean people like Billy Joel for instance recently he said that he regrets he actually can't play, he actually can't read music, so I think that, if you've trained classically, then that's good because it makes you much stronger.

Those who achieved this degree of structure and learning development could adaptively and reflexively cope with a variety of situations and deal with contingency and the unexpected, which was termed their relative adaptive capacity. In the course of the professional doctorate, candidates often found themselves coping with unexpected changes. A prime example of this was in 2010, when the UK government changed from Labour to a coalition led by the Conservative Party, which resulted in public spending cuts; several doctoral candidates found funding for their doctoral projects decreased or entirely withdrawn. Interestingly, rather than seeing this as problematic, many saw this as a challenge and found that their work could transcend these particular constraints both in terms of the thrust of their work and their overarching ideas and also in terms of their methodological approaches. One candidate explicitly turned this to his advantage:

Of course we got the change of government and they scrapped the whole programme...I had a tough week or two thinking this is all going to be a complete waste of time but, then, it kind of shook out into the fact that, well, the schools have still got to do something. In fact without the government programme, schools are left high and dry, what are they going to do? So in actual fact.... am probably going to be able to have more impact as an individual than I would have done in the past...it's going to be different.

\section{Discussion}

Burgess et al. (2013), in their discussion of the experience of professional doctoral candidates, posit that many of the attributes and skills of the workplace demonstrate a key 
tension with those of the academic world. For example, criticality is a skill valued across all academic study yet the workplace often requires responsive and rapid decisions to be made with a degree of immediacy and intuition. This can present challenges for the candidate who has already developed and established these skills and then enters a doctoral programme to discover they need to develop the capacity to use a new and different skill set. Similarly, they need to develop the skill of academic writing and they often arrive at HEls with several years experience of effective report writing in a bureaucratic environment with minimal scope for creativity in writing.

The most salient finding of the study was that progressive development of a foundational solid base of transferable skills, underpinned by incorporating methodological approaches integrated with the skills of critical reflection, allowed doctoral candidates to develop their individual practice in a uniquely creative manner. Although the term 'doctoralness' did not feature in the interviews; it was this very attribute that was fostered. Trafford and Leshem (2009) attempted to operationally define 'doctoralness' and, whilst they identified various attributes of the concept, they highlighted that it is the synergy of these attributes which provides resultant 'doctoralness'. The integration of these skills is essential but, as a precursor, doctoral candidates must first develop this foundational capability, which is why the taught element of the programme is of fundamental significance to the student's developmental learning trajectory.

Many of the candidates found the academic requirements of the programme, in tandem with the demands of work, challenging. Prevalent discourses often differed between doctoral study and the workplace. For example scholarship and critical evaluation were often valued in the academic context of the university, whilst innovation and responsiveness were evidently more dominant in work-based settings. Candidates developed a high degree of critical reflexivity, which became the cornerstone of their study and allowed an integration of the many emergent divergent themes. This critical reflexivity facilitated doctoral candidates in balancing the multiple perspectives of their studies and their capacity for negotiation of them.

Professional doctoral candidates, whilst often familiarised to a great extent with the compilation of work-based reports, can often find the additional requirements of academic writing both novel and challenging. Jones' (2013) work reveals that the significance of the 
development of skills demonstrating doctoral credibility in writing and research for PhD candidates, is equally as transferrable to professional doctoral candidates.

As long ago as 2002, Fook acknowledged the advent of a post-modernist world and contended that professional practice and professional development ought also to be regarded in this context (Fook, 2002). In keeping with this line of thought Lester (2015) proposed models of professionalism of direct relevance to this discussion. The first is the "technocratic model" or techno-rational, a by-product of the industrial revolution, which purposefully seeks rational, standard and formal methods. His second model is reflective or creative-interpretative, where professionals are faced with a rapidly changing world where they must contend with dealing creatively and responsively to real life problems. This is the world, in which the work-based professional doctoral candidates find themselves immersed, where they need to dynamically develop their practice via the use of creative and fundamentally unique approaches.

The process of reflection is also a significant and integral part of the development of the work-based professional doctoral programme. Each student needs to explore and develop their practice, and part of this is to introspectively examine the process of their career in the context of their wider unique contribution to practice. However a common theme throughout the interviews, especially from those working in the public sector, was the dynamic nature and changing circumstances of what constituted work and the precarious nature of utilising funding from projects which could often be withdrawn with little or no prior warning. Reflective practice needs to enable the candidate to move beyond the immediate and see the wider social forces which can inevitably impinge on practice. This has been referred to as 'critical reflection' by many writers (Fook, 2007). This potentially consolidates the work around authenticity that has become such a ready focus in the consideration of professional doctoral pathways in recent years (Herrington, Reeves and Oliver, 2014).

Within reflection and reflective accounts, there was the need for an integration of reflection with methodological approach in a manner which would drive forward momentum of the work trajectory and at the same time demonstrate a tangible degree of logic and consistency. This was another major identifiable challenge. Methodological approaches such as action research are useful, as reflection is integrated in this approach and the 
researchers can proactively guide and direct the process as it emerges. Another, less common approach is autoethnography. Practice-based research involves working in practice and describing, analysing and evaluating that practice and is, by definition, ethnographic. Reflexivity is a major part of ethnography and ethnographic approaches and the part of the researcher in the research setting, the analysis of data and the writing and presentation of the data are considered central to the process (Lichterman, 2015). These core characteristics frame autoethnography as an appropriate methodology for integration into the professional doctoral programme.

The programme evaluated in this study, focuses on experiential learning and as such promotes reflection on practice and there is a strong emphasis on the shaping and development of the work-based project. There is recognition that to effectively develop the project there needs to be a framework or recognised methodology which fundamentally underpins this development. The candidates who were interviewed indicated how helpful these modules were in the development of their work. However, it must be acknowledged that they report these perceptions through the lens of hindsight and, to a certain extent, maturation of viewpoint may be evident. Nonetheless the taught component was perceived to effectively facilitate the development of work-based projects.

The development of practice, by its very definition, is focused on the relatively nebulous and complex world of work. Yet, one of this study's findings clearly demonstrated the need for a methodological framework to underpin the development of this potentially ambiguous work and this was one of the key challenges for address. It is a contradiction in terms to suggest that the work-based professional doctorate should be encapsulated in a specific methodological position rather than a philosophical stance. Dealing with contingency and the unforeseen effectively and through the use of higher order critical thinking is a core characteristic of a highly functioning worker, regardless of context. Even people working in highly technical or skills oriented working environments are expected to deal with ambiguity which necessitates adaptive flexibility. MacLean et al. (2002) discuss methodological approaches to the development of 'Mode 2' knowledge and suggest action research, clinical method, grounded theory and co-operative enquiry as appropriate means of addressing this challenge. In this study the candidates interviewed selected approaches such as action research, case study and mixed methods. Bricolage (the use of a number of epistemological approaches within one study or project) is particularly relevant to the 
professional doctorate programme and in particular how the combination of training and development from multiple perspectives could be improved and developed in educational practice.

Much has been written about supervision in the context of the PhD but not so much has been written around supervision within the context of the Professional Doctorate (or workbased professional doctorate). It is far too simplistic to polarise the $\mathrm{PhD}$ and the Professional Doctorate since the reality of their differences is inherently more complex than it first seems. Sinclair (2004) carried out a review of supervision within the context of the PhD and found that the discipline could strongly influence the nature of the supervisory experience. Natural Science, where a more directive approach is involved, had better outcomes than those doctoral candidates in the humanities and social sciences. Pearson and Brew (2002) discuss supervision and suggest a training package for supervisors, which promotes both awareness of learning and reflection as key components. Sambrook, Stewart and Roberts (2008) discuss the ways in which the supervisory process can facilitate the construction of knowledge and the need to create the atmosphere in which this can take place. Translating these findings into the professional doctorate scenario is not straightforward but supervision does seem to be a key component and factors that promote a satisfactory supervisory relationship can be highlighted as a potential area of further research.

\section{Conclusion}

The candidates being studied belong to a specific cohort of a work-based professional doctorate programme and, as such, develop their professional practice via intrinsic motivation to drive their professional contribution to practice forward, using the context of their studies as a vehicle. From our perspective as educators and facilitators of learning development, doctoral candidates needed individually tailored guidance and a clear focus on the underpinning skills. As they moved through the programme the supervisors increasingly became key figures in the doctoral journey. The sample size of this study was relatively small, however the three most salient areas for consideration from the study were clearly identifiable as: 
- The nature of the supervisory relationship and what constitutes good practice.

- The capacity for criticality necessary to undertake reflection as a doctoral candidate.

- The need for doctoral candidates to have enhanced levels of learning and teaching in relation to the establishment of focused overarching methodological frameworks.

Engagement with the entirety of the programme, incorporating both taught elements and supervision, is essential for doctoral candidates. The process of facilitation they are exposed to aids them in the development of the practical research skills they will subsequently use to refine and develop their professional practice. The work involved in the professional doctorate is indisputably of doctoral standard and is directly comparable with work submitted on alternative doctorate programmes and candidates demonstrate this by meeting the standards for doctoral work (QAA, 2011). Reflections on both the process and product, combined and integrated with the methodological approach, framed practice development initiatives. This fostered and developed the students' ability to position themselves beyond the immediate, so that when the (seminally described) 'wicked' problems of professional practice (Rittel and Webber 1973; Lester 2004) come along, their work could be contextualised and thereby transcend the particularly difficult and problematic areas of practice.

\section{References}

Benlow, S. (2015) '“Have it your way”: consumerism invades education', in Mauk, J. and Metz, J. (2015) The composition of everyday life. Mason, $\mathrm{OH}$ : Cengage Learning Inc, pp. 139.

Bimrose, J., Brown, A., Holocher-Ertl, T., Kieslinger, B., Kunzmann, C., Prilla, M., Schmidt, A., Wolf, C. (2014) 'Introducing learning innovation in public employment services: what role can facilitation play?', International conference on e-learning in the workplace (ICELW). Columbia University, New York 11-13 June. Available at: https://pdfs.semanticscholar.org/81e7/6d3cedd40624dcd1c0b411451f6cd003fb8e.p df (Accessed: 12 February 2017). 
Burgess, H., Weller, G. and Wellington, J. (2013) 'The connection between professional doctorates and the work place: symbiotic relationship or loose association', Work Based Learning e-Journal International, 3(1), pp. 76-108.

Conn, V. S. (2014) 'Prepare to launch optimizing doctoral education to ensure career success. Western Journal of Nursing Research, 36(1), pp. 3-5. https://doi.org/10.1177/0193945913492652

Costley, C. and Lester, S. (2012) 'Work-based doctorates: professional extension at the highest levels', Studies in Higher Education, 37(3), pp. 257-269. http://dx.doi.org/10.1080/03075079.2010.503344

Costley, C. and Stephenson, J. (2007) 'The impact of a professional doctorate centred on the candidates' work', Work Based Learning e-journal International, pp. 1-15. Available at: http://www.wblearningejournal.com/costleystephensonfullpaper2forjournal.pdf (Accessed: 5 March 2017).

Doncaster, K. and Lester, S. (2002) 'Capacity and its development: experiences from a work-based doctorate', Studies in Higher Education, 27(1), pp. 91-101. http://dx.doi.org/10.1080/03075070120099395

Dowling, D. A. (2015) The Dowling review of business-university research collaborations (BIS/15/352). Available at https://www.gov.uk/government/publications/businessuniversity-research-collaborations-dowling-review-final-report (Accessed: 13 February 2017).

Drucker, P.F. (1999) Management challenges for the 21st century. Oxford: ButterworthHeinemann.

Fink, D. (2006) 'The professional doctorate: its relativity to the Ph.D. and relevance for the knowledge economy', International Journal of Doctoral Studies, Vol 1, pp. 35-44. Available at: http://www.ijds.org/Volume1/IJDSv1p035-044Fink14.pdf (Accessed: 13 February 2017). 
Fook, J. and Gardiner, F. (2007) Practising critical reflection: a resource handbook. Maidenhead: Open University Press.

Fook, J. (2002) 'Theorizing from practice: towards an inclusive approach for social work research', Qualitative Social Work, 1(1), pp. 79-95. https://doi.org/10.1177/147332500200100106

Fulton, J., Kuit, J., Sanders, G. and Smith, P. (2012) 'The role of the professional doctorate in developing professional practice', Journal of Nursing Management, 20(1), pp. 130-139. https://doi.org/10.1111/j.1365-2834.2011.01345.x

Gibbons, M., Limoges, C., Nowotny, H., Schwartzman, S. and Scott, P. (1994) The new production of knowledge: the dynamics of science and research in contemporary societies. London: Sage.

Gill, G.T. and Hoppe, U. (2009) 'The business professional doctorate as an informing channel: a survey and analysis', International Journal of Doctoral Studies, Vol 4, pp. 27-57. Available at: http://www.ijds.org/Volume4/IJDSv4p027-057Gill267.pdf (Accessed: 13 February 2017).

Glaser, B. and Strauss, A. L. (1967) The discovery of grounded theory: strategies for qualitative research. Chicago: Aldine Publishing Company.

Hakkarainen, K. P., Wires, S., Keskinen, J., Paavola, S., Pohjola, P., Lonka, K. and Pyhältö, K. (2014) 'On personal and collective dimensions of agency in doctoral training: medicine and natural science programs', Studies in Continuing Education, 36(1), pp. 83-100. http://dx.doi.org/10.1080/0158037X.2013.787982

Herrington, J., Reeves, T. C. and Oliver, R. (2014) Authentic learning environments, in Spector, J. M., Meerrill, D. M., Elen, J. and Bishop, J. M. (eds.) Handbook of research on educational communications and technology. New York: Springer, pp. 401-412. 
Jones, M. (2013) 'Issues in doctoral studies - forty years of journal discussion: where have we been and where are we going?', International Journal of Doctoral Studies, Vol 8, pp. 83-104. Available at: http://ijds.org/Volume8/IJDSv8p083-104JonesFT129.pdf (Accessed: 13 February 2017).

Kamler, B. and Thomson, P. (2014) Helping doctoral candidates write: pedagogies for supervision. $2^{\text {nd }}$ edn. Oxon: Routledge.

Lester, S. (2004) 'Conceptualising the practitioner doctorate', Studies in Higher Education, 29(6), pp. 757-770. http://dx.doi.org/10.1080/0307507042000287249

Lester, S. (2015) On professions and being professional available. Available at: http://devmts.org.uk/profnal.pdf (Accessed: 13 February 2017).

Lichterman, P. (2015) 'Interpretive reflexivity in ethnography', Ethnography, 0(00), pp.1-11. https://doi.org/10.1177/1466138115592418

Labov, W. and Waletzky, J. (1967) 'Narrative analysis: oral versions of personal experience', in Helm, J. (ed.) Essays on the verbal and visual arts. Seattle: University of Washington Press, pp. 12-44.

MacLean, D., Maclntosh, R. and Grant S. (2002) 'Mode 2 management research', British Journal of Management, 13(3), pp. 189-207. https://doi.org/10.1111/14678551.00237

Matheson, D. (2005) Media Discourses: analysing media texts. Maidenhead: OU Press.

Maxwell, T. (2003) 'From first to second generation professional doctorates', Studies in Higher Education, 28(3), pp. 279-291. http://dx.doi.org/10.1080/03075070309292

Pearson, M. and Brew, A. (2002) 'Research training and supervision development', Studies in Higher Education, 27(2), pp. 135-150. http://dx.doi.org/10.1080/03075070220119986c 
Quality Assurance Agency for Higher Education (2011) Doctoral Degree Characteristics. Available at:

http://www.qaa.ac.uk/en/Publications/Documents/Doctoral_Characteristics.pdf (Accessed: 13 February 2017).

Rittel, H. and Webber, M. (1973) 'Dilemmas in a general theory of planning', Policy Sciences, 4(2), pp. 155-169. http://dx.doi.org/10.1007/BF01405730

Roberts, G. (2002) SET for Success. London: HM Treasury. Available at: http://webarchive.nationalarchives.gov.uk/+/http:/www.hmtreasury.gov.uk/set_for_success.htm (Accessed: 13 February 2017).

Scott, P. (1997) 'The changing role of the university in the production of new knowledge', Tertiary Education and Management, 3(1), pp. 5-14.

Sambrook, S., Stewart, J. and Roberts, C. (2008) 'Doctoral supervision... a view from above, below and the middle!', Journal of Further and Higher Education, 32(1), pp. 71-84. http://dx.doi.org/10.1080/03098770701781473

Schildkraut, J. and Stafford, M. C. (2015) 'Researching professionals or professional researchers? A comparison of professional doctorate and $\mathrm{PhD}$ programs in criminology and criminal justice', American Journal of Criminal Justice, 40(1), pp. 183-198. http://dx.doi.org/10.1007/s12103-014-9240-z

Sinclair, M. (2004) The pedagogy of 'good' PhD supervision: a national cross-disciplinary investigation of PhD supervision. Canberra: Department of Education, Science and Training, Australian Government. Available at:

http://w3.unisa.edu.au/researcheducation/supervisors/documents/phd_supervision. pdf (Accessed: 13 February 2017).

Strauss, A. and Corbin, J. (1998) Basics of qualitative research: techniques and procedures for developing grounded theory. London: Sage. 
Stubb, J., Pyhältö, K. and Lonka, K. (2014) 'Conceptions of research: the doctoral student experience in three domains', Studies in Higher Education, 39(2), pp. 251-264. http://dx.doi.org/10.1080/03075079.2011.651449

Trafford, V. and Leshem, S. (2009) 'Doctorateness as a threshold concept', Innovations in Education and Teaching International, 46(3), pp. 305-316.

http://dx.doi.org/10.1080/14703290903069027

Van Dijk, T. (2008) Discourse and Power. London: Palgrave.

\section{Author details}

Dr John Fulton is a Reader in Practice Based Research in the Faculty of Health Sciences and Wellbeing at the University of Sunderland.

Dr Catherine Hayes is a Reader in Pedagogic Practice in the Faculty of Health Sciences and Wellbeing at the University of Sunderland. 